\title{
Sublingual Salivary Gland
}

National Cancer Institute

\section{Source}

National Cancer Institute. Sublingual Salivary Gland. NCI Thesaurus. Code C12234.

A salivary gland located under the tongue in the floor of the oral cavity. 